\title{
The Relationship Among Associate Pastor's Calling, Pastoral Stress, Self-Esteem and Job Satisfaction
}

\author{
Hyoung-Woon $\mathrm{Cho}^{1}$ and Hyoun-Yong Kwon ${ }^{2 *}$ \\ ${ }^{1}$ Dept. Student Support Office, Calvin Univ., 184, Mabuk-ro, Giheung-gu, Yongin-si, \\ Gyeonggi-do, Republic of Korea \\ ${ }^{2}$ Dept. Liberal Arts \& Education, Hyupsung Univ., 72, Choerubaek-ro, Bongdam-eup, \\ Hwaseong-si, Gyeonggi-do, Korea \\ 1'chohw19@hanmail.net, ${ }^{2}$ khyong@hanmail.net
}

\begin{abstract}
This study aims to acknowledge the relationship between the sense of calling and pastoral stress, self-esteem and job satisfaction. For this, 583 assistant pastors were surveyed using random sampling, 487 final results were used for the final analysis for except the insincere ones. The results of the study are as follows. First, as a result of observing the kind of influence on an assistant pastor's sense of calling, pastoral stress, self-esteem on job satisfaction, the explanatory power that explains an assistant pastor's job satisfaction is high in the order of pastoral stress, self-esteem, and sense of calling. Secondly, after observing the results of the intermediary role between the assistant pastor's sense of calling, pastoral stress, self-esteem and job satisfaction, the sense of calling gives a significant influence on job satisfaction by the medium of pastoral stress and self-esteem, and it shows the indirect mediated effect.
\end{abstract}

Keywords: Assistant pastor, Sense of calling, Pastoral stress, Self-Esteem, Job satisfaction

\section{Introduction}

Korean church associates are dedicated to the growth of the church, including preaching, dioceses, administration, education, planning, visits, and missions. They are suffering from exhaustion of physical energy, anxiety about the uncertain future, the structural environment of the ministry and conflict with church members, and the low cost of the church. The associate pastors of the Korean churches are frequently moved to churches, and it is difficult to find cases where the pastors have worked in a church for more than 10 years. In particular, educational evangelists rarely work in a church for more than five years [1]. Although associate workers have specialized knowledge and skills, treatment and reality are very poor. According to data from the press conference presentation on the Model of Ministerial Work Contracts published by the Christian Ethics Movement, $73.6 \%$ of non-Teachers have no support for the four major insurance policies [2]. In reality, there is a lack of support for assistant pastors.

Specifically, the role of assistant pastor plays a role of expertise in the fields of administration, mission, education, visitation, counseling, etc. [3], and breaks down vertical leadership in the community and insists on leadership in working together. The helper-ship of

Article history:

Received (March 31, 2019), Review Result (July 7, 2019), Accepted (November 22, 2019) 
teachers and assistants plays a role in harmony [4]. However, associate ministers spend a lot of working time thinking that they must devote themselves and sacrifice for the growth of the church and face various stresses such as poor working environment, excessive work, anxiety about the future, and conflict with church members [5]. The assistant pastor is experiencing psychological difficulties because of irregular tasks such as administration and preaching according to the schedule of the homeroom teacher, and the difficulty is increasing due to the low cost of earning a living [6].

In order to perform the duties, the assistant pastor must examine whether he is adequately qualified for ministry and has been called by God. Calling means being called for some special purpose. Martin Luther and John Calvin used the Christian religious concept of God's "calling" people through their work [7]. Calling is a very important concept for Christians because it refers to all actions that follow the will of God [8].

Associate ministers are called to perform their duties, but due to energy exhaustion, excessive church demands, financial problems, church growthist values, pastoral structure, pastoral and family problems, etc. I have a variety of pastoral stresses. The assistant pastor is a contractor, and his professionalism and autonomy of the pastoral ministry are not guaranteed due to the instability of the term and the pastor-centered ministry [9]. Pastoral stress of associate workers affects satisfaction in the personal, family, and church domains.

On the other hand, self-esteem has a variety of influences on the work performed by associate workers [10]. Self-esteem means self-esteem that one can achieve results in relation to work by recognizing one's sense of value [11] and a person who has high self-esteem can positively conceptualize that he is valuable. In addition, because they see themselves as capable of coping with the world they perceive and act confidently in their own situation, they can lead a positive social life and live actively. Prior studies of job satisfaction and selfesteem showed a positive correlation between job satisfaction and self-esteem [12], selfrespect as an internal motivation factor positively affects job satisfaction [13].

The job satisfaction of the associate ministers can be said to be high when they are given autonomy, support and encouragement of their teachers, co-operation, full support of their work resources, recognition of members, and appropriate compensation. In general, job satisfaction is the mental state of emotion generated by the level of satisfaction of job-related needs perceived by the individual. In addition, job satisfaction is a personal attitude toward the job, which is a satisfactory or positive employee's evaluation of his / her job. Emotional state [14][15].

The purpose of this study is to examine the relationship between the calling vocation of pastors, pastoral stress, self-esteem and job satisfaction. The purpose of this study is to examine the relationship between vocational calling, pastoral stress, self-esteem, and job satisfaction of the assistant pastors, and the mediating effects of pastoral stress and selfesteem. The purpose of this study is to provide a deeper understanding of the work of the assistant pastors and provide them as a basis for realistic support and better job development for them.

In order to achieve this purpose, the following research questions were set.

1. Are there differences in calling, pastoral stress, self-esteem, and job satisfaction according to the demographic characteristics of the assistant pastors?

2. How do the calling, pastoral stress and self-esteem of the assistant pastors affect job satisfaction?

3. What mediating effects does the calling, pastoral stress and self-esteem of the assistant pastors have on job satisfaction? 


\section{Research method}

\subsection{Subjects}

The subjects of the study were a random survey of 583 the assistant pastors from all over the country using a random sampling method. Of these, 487 copies were used for the final analysis. Specifically, the genders were 414 males (85.0\%), 73 females (15.0\%), 158 males (32.4\%) under 30 years of age, 247 females (50.7\%), 31-40 years old, and 41-50 years old. 38 $(7.8 \%)$ and $44(51 \%)$ or older (51\%). Marital status was 254 unmarried (52.2\%), 233 married (47.8\%), $182(37.4 \%)$ with or without children and $305(62.6 \%)$ without children. The education level was 57 graduates (11.7\%), 399 graduates $(81.9 \%)$, and 31 graduates $(6.4 \%)$. The job titles were $345(70.8 \%)$ educators, $13(2.7 \%)$ visiting ministry, $11(2.3 \%)$ preacher, $70(14.4 \%)$ associates, and $48(9.9 \%)$ others. Table 1 offers the general characteristics of the subject with regard to demographic sociology.

\subsection{Measurement Scale}

To measure the Calling, the scale of the vocation of Calling and Vocation Questionnaire (CVQ) developed by Dik, Eldridge and Steger [16] was revised and modified by Sim Ye-rin and Yu Sung-kyung [17] and newly developed according to the Korean situation (CVQ). -K) was used. As a result of reliability analysis, Cronbach 's showed transcendental callingexistence .53 , purpose/meaning-existence .67 , prosocial orientation-being.

In order to measure the pastoral stress, the pastoral stress developed by Lim Kyung-seop [18] was revised and supplemented with a total of 61 questions (14 sub-factors). 54 questions (14 sub-factors) were constructed through content validity. Finally, we developed a pastoral stress scale with 31 questions (7 sub-factors). As a result of reliability analysis, Cronbach's scores of family stress .88 , church pastoral stress .85 , ministry stress .86 , personal spiritual stress .76, church faith stress .79, life stress .74, church growth stress .76, total .92 .

To measure self-esteem, we used a tool translated by Jeon Byung-jae [19] on the SelfEsteem Scale developed by Rosenberg [20]. As a result of reliability analysis, Cronbach 's was .82 .

In order to measure job satisfaction, Park Ki-hyeon [21] developed teachers and Tak Kyung-sung [22] revised and revised the scale for pastors. As a result of the reliability analysis, Cronbach 's score was .69, denomination organization .69, social recognition and economic problem .82, self-explanation .55, self-development .26, and human relationship .65.

\subsection{Analysis of materials}

SPSS version 23 and Amos version 23 Programs were used to analyze the relationship among the sense of calling and pastoral stress, self-esteem and job satisfaction. Independent sample t-tests and one-way ANOVA were performed to verify differences in key variables according to demographic and statistical characteristics. A hierarchical regression analysis was conducted to examine the effects of calling, pastoral stress and self-esteem on job satisfaction. In addition, in order to confirm whether the data is suitable for structural model analysis, the measurement model was verified through the path analysis of the measurement model, and the structural equation model was used to compare the fit of the research model with the competition model. The effect was verified. 


\section{Result of research}

\subsection{The Effects of calling, pastoral stress and self-respect on job satisfaction}

Hierarchical regression analysis was performed to find out which of the sub-variables of vocation, pastoral stress and self-esteem are better explained by job satisfaction. As a result of examining the vocation, pastoral stress, and self-esteem, which affect job satisfaction, among the 11 variables, the purpose/meaning, ministry stress, life stress, and self-esteem among four variables were It was found to have a significant effect. The variables with high explanatory power centered on R2 change were ministry stress, life stress, purpose/meaning, and selfesteem.

\subsection{Mediating effects of calling, pastoral stress, and self-esteem on associate satisfaction}

Before verifying the measurement model by conducting the path analysis of the measurement model, the path analysis of the measurement model was conducted. The suitability of the measurement model was examined by focusing on TLI, CFI, RMSEA, and SRMR. TLI [23], like CFI, judges good fit if it is above .90. As a result of the analysis, the fitness index was confirmed after using the Modification Index method which allowed the error covariance between measurement variables because all of the fitness indexes were slightly below the standard values. As shown in Table 6 , TLI $=.905$, CFI $=.932$, RMSEA $=.064$, and SRMR $=.054$, indicating that the measurement model is suitable.

First of all, the direct effect is on pastoral stress $(\beta=-.65, \mathrm{p}<.001)$, self-esteem $(\beta=.61, \mathrm{p}$ $<.001)$, job satisfaction $(\beta=.34, \mathrm{p}<.01)$. There was a significant direct effect. In addition, pastoral stress had a direct effect on job satisfaction $(\beta=-.35, \mathrm{p}<.001)$ and self-esteem had a direct effect on job satisfaction $(\beta=.16, \mathrm{p}<.05)$. Next, the indirect effect estimated by using bootstrapping showed that the sense of vocation has a significant indirect effect on job satisfaction $(\beta=.67, \mathrm{p}<.01)$.

Sobel-Test was conducted to analyze the mediated effects and the results are shown in Table 8 . As a result, the sense of calling is indirect path $(\beta=.23, p<.001)$ through pastoral stress and job satisfaction. In the previous analysis, because calling also directly explains pastoral stress, pastoral stress is the relationship between calling and job satisfaction. It was found to partially mediate. In addition, since self-esteem is indirect path $(\beta=.10, p<.05)$ to self-esteem, it is confirmed that self-esteem partially mediates the relationship between selfesteem and job satisfaction.

\section{Conclusion \& discussion}

First, hierarchical regression analysis was conducted to verify the effect of calling, pastoral stress and self-esteem on job satisfaction. The results were ministry stress, life stress, purpose/meaning, and self-esteem. In order to increase job satisfaction, it is necessary to approach ministry stress, life stress, purpose/meaning, and self-esteem, and suggest that selfesteem and vocation are both important factors to enhance job satisfaction rather than considering only one factor of pastoral stress. Jang Hyung-Seok [24] found that people who recognize the meaning of work are more satisfied with their job and life, and that the job stress is related to psychiatric symptoms [25]. The same is true with previous studies that reported an impact. In general, it is thought that the sense of vocation is the most influential factor in the job satisfaction of the assistant pastors, but the study stresses that the ministry 
stress and life stress, which are sub-factors of pastoral stress, have the most influence. This can be understood as a job environmental factor for associate workers.

Second, as a result of statistically verifying whether the pastoral stress has a mediating effect in the relationship between the sense of calling and the job satisfaction, the sense of calling has a significant effect on the job satisfaction through the pastoral stress. In other words, the sense of vocation was found to partially mediate job satisfaction through pastoral stress. This implies that pastoral stress has an influence on the level of job satisfaction affecting job satisfaction, which is consistent with the results of previous studies that the higher the job stress, the lower the job satisfaction [26]. After all, pastoral stress affects job satisfaction just as job stress affects job satisfaction. The associates do their jobs with a sense of calling, but they experience pastoral stress because of the actual situation and perceptions of them. Therefore, it is important to reduce pastoral stress and increase calling vocation in order to increase job satisfaction of associate workers.

\section{References}

[1] The Christian Newspaper, "The graveness of downtown Mega-Church concentration phenomenon," November 08, 2017, Retrieved from http://www.gdknews.kr/n_news/news/ view.html?no=2554, November 08 (2017)

[2] Christian Ethics Movement, Assistant Pastor's Ministry Contract Model Press Conference, Christian Ethics Practice Campaign, 06, 10, (2016),

[3] Y. H. Koh, "A study on church growth and the role of an assistant pastor: Based on associate pastor," M.S. thesis, Anyang University, Anyang, Republic of Korea, (2010)

[4] Y. J. Lee, “A Study on the Influence of a Senior Pastor's Leadership and an Assistant Pastor's Helpership on Church Growth, PH.D. thesis," Calvin University, Yong-in, Republic of Korea, (2016)

[5] S. R. Seo, "A study on the Correlation of an assistant pastor as a helper and church growth," Ph.D. Dissertation, Hanshin University, Osan, Republic of Korea, (2008)

[6] K. S. Kim, "An understanding and handling for the burn out of assistant pastors, Master's thesis," Methodist Theological University, Seoul, Republic of Korea, (2012)

[7] Bryan J. Dik, and Ryan D. Duffy, "Calling and vocation at work: Definitions and prospects for research and practice," The Counseling Psychologist, vol.37, no.3, pp.424-450, (2009)

[8] S. D. Min, "The effect of a christian career counseling program on a christian undergraduate's vocation and career identity,” Ph.D. Dissertation, Korean Bible University, Seoul, Republic of Korea, (2016)

[9] J. W. Park, "A study on an assistant Pastor's working environment and stress as an ethical problem in a Christian society," The Korean Journal of Christian Social Ethics, vol.26, pp.117-147, (2013)

[10] S. M. Lee, "The influence of a nurse's Self-Esteem and communication ability on job satisfaction," Ph.D.thesis," Ajou University, Seoul, Republic of Korea, (2015)

[11] C. J. Kim and M. K. Kim, "A study on the tendency and correlation of Self-Esteem and course maturity based on the sex of middle school students," The Journal of Educational Research, pp.1-21, (2009)

[12] J. H. Min, "The impact of municipal hospital nurses' self-esteem on professional self-concept and job satisfaction, Master's thesis," Catholic University, Seoul, Republic of Korea, (2015)

[13] S. A. Ryu, S. H. Moon, J. S. Choi, and B. H. Kim, "The influence of an awareness of Mentally-Disordered Person's recovery," Self-Esteem and Role-Performance on Job Satisfaction that a Psychiatric \& Mental Health Nurse Realizes, Korean Academy of Nursing Administration, vol.18, no.4, pp.434-441, (2012)

[14] J. H. No, "A study on the conceptualization and measurement of faculty job satisfaction," The Journal of Educational Administration, vol.19, no.2, pp.163-181, (2001)

[15] N. H. Park, “Organizational Behavior," Seoul: Parkyoungsa, (2003) 
[16] Bryan J. Dik, Brandy M. Eldridge, and Michael F. Steger, Development of the Calling and Vocation Questionnaire (CVQ), Paper presented at the meetings of the American Psychological Association. Boston, MA, (2008)

[17] Y. L. Sim, and S. K. Yu, "Development and validation of the Korean Version of the Calling and Vocation Questionnaire (CVQ-K)," Korean Psychological Association, vol.24, no.4, pp.874-872, (2012)

[18] K. S. Lim, "A study on a Pastor and a Pastor's Wife on the stress and coping plan," S.D. thesis," Inha University, Incheon, Republic of Korea, (1997)

[19] B. J. Jeon, “A Study on the possibility of Self-Concept measurement,” Yonsei Journal, vol.11, pp.109-129, (1974)

[20] M, Rosenberg, "Society and the adolescent Self-Image," Princeton, NJ: Princeton university, (1965)

[21] K. H. Park, "A Study on the job satisfaction of a commercial high school teacher, Master's thesis," Yonsei University, Seoul, Republic of Korea, (1994)

[22] K. S. Tak, “A study on a Pastor's Job satisfaction centered on ministerial environment," Pd.f. dissertation. thesis," Yonsei University, Seoul, Republic of Korea, (1996)

[23] L. R. Tucker, and C. Lewis, "A reliability coefficient for maximum likelihood factor analysis. Psychometrika," vol.38, no.1, pp.1-10, (1973)

[24] H. S. Jang, "The difference between the sense of purpose in life based on the degree of meaning in job satisfaction and job," Pusan National University's Institute of Student Life, vol.33, pp.137-158, (2001)

[25] M. J. Son, "A study on the influence of a stress of a Pastor's wife on depression: Mediated effect of selfesteem verified," Ph.D. thesis, Sungkyul University, Anyang, Republic of Korea, (2014)

[26] M. A. Chu and Y. A. Chang, "The job satisfaction of a childcare teacher on childcare efficacy and the influence of job stress," The Korean Journal of Community Living Science, Vol.20 No.3, pp.343-355. (2009) 